\title{
Resident assessment facilitation team: collaborative support for activated learning
}

\author{
Elissa Foster, ${ }^{1}$ Nicole Defenbaugh, ${ }^{2}$ Susan E. Hansen, ${ }^{3}$ Nyann Biery, ${ }^{3}$ Julie Dostal ${ }^{3,4}$ \\ ${ }^{1}$ DePaul University College of Communication, Chicago, IL; ${ }^{2}$ Clinical Communication Educator, Allentown, PA; ${ }^{3}$ Lehigh Valley Health \\ Network Department of Family Medicine, Allentown, PA; ${ }^{4}$ Morsani College of Medicine, University of South Florida, Allentown, PA, USA
}

Correspondence: Elissa Foster, DePaul University College of Communication, 14 E. Jackson Blvd, Chicago, IL 60604, USA. Tel.: +1.312.362-8954.

E-mail: commscholar@hotmail.com

Key words: advising, clinical competency committee, self-assessment, adult learning.

Contributions: EF was the primary author for the article. She was involved in all aspects of the article: concept, design, analysis, interpretation, writing and editing. EF drafted the first draft of the document with input from the other authors. She edited the manuscript and approves of the final version to be published. EF agrees to be accountable for all aspects of the work. ND was also involved in every aspect of the manuscript including its concept, design, analysis, interpretation, writing, and editing. ND approved of the final version to be published and agrees to be accountable for all aspects of the work. SH was involved in the concept and design of the paper and participated in the analysis and editing of the manuscript. SH approved of the final version to be published and agrees to be accountable for all aspects of the work. NB assisted with the concept and design of the paper and participated in the analysis. She approved of the final version to be published and agrees to be accountable for all aspects of the work. JD was involved in the concept and design of the article. She also participated in the analysis of the data and writing portions of the manuscript. She edited the manuscript and approved the final version to be published. JD agreed to be accountable for all aspects of the work.

Conflict of interest: the authors declare no potential conflict of interest.

Funding: this research was supported by funding from the Dorothy Rider Pool Health Care Trust and the Faculty Research and Development Program, College of Communication, DePaul University.

Acknowledgements: the authors wish to acknowledge Drew Keister, MD and Jacqueline Grove at Lehigh Valley Health Network for their assistance in the preparation of this article, and the residents and faculty of the Family Medicine Residency at Lehigh Valley Health Network who participated in RAFT meetings and gave their permission to record and analyze their interaction. The research conducted in this manuscript was approved by the Lehigh Valley Health Network (LVHN) Institutional Review Board and complies with the WMA Declaration of Helsinki. Informed consent to participate in the research was obtained by all participants and their anonymity was ensured throughout the research process. The LVHN IRB approved the human subjects determination and our compliance with ethical standards of research. There was no conflict of interest for the authors.

Received for publication: 21 July 2017.

Revision received: 5 January 2018.

Accepted for publication: 5 January 2018.

This work is licensed under a Creative Commons Attribution NonCommercial 4.0 License (CC BY-NC 4.0).

CCopyright E. Foster et al., 2017

Licensee PAGEPress, Italy

Qualitative Research in Medicine \& Healthcare 2017; 1:109-120

doi:10.4081/qrmh.2017.6944

\begin{abstract}
Because healthcare knowledge, practices and systems change so rapidly, physicians-in-training need to develop skills related to lifelong learning. The adult learning paradigm defines the effective professional learner as autonomous and activated. A part of the residency's $p^{4}$ (Preparing the Personal Physician for Practice) redesign, the RAFT (Resident Assessment Facilitation Team) process was designed to encourage residents' adoption of activated learning behaviors by incorporating their participation in team-based educational planning and assessment of competence. This study examined interaction within the RAFT meetings to guage residents' adoption of activated learning behaviors over time. In this study, transcripts of RAFT meetings from a single cohort of residents during the first and third years of training were analyzed using a grounded theory approach. Teams of at least two analysts per transcript engaged in two rounds of descriptive coding and three levels of axial coding to examine interaction during the RAFT meetings and identify how that interaction was related to residents' activated learning. Four categories of interaction were identified: advising, managing the process of the meeting, expressing and managing emotion, and demonstrating reflective practice and mindfulness. Across those categories, 36 sub-types of messages indicated both similarities and differences between first- and third-year residents. Specifically, third-year residents took a more active leadership role in meetings; faculty team members were more likely to hand over responsibility for problem solving to thirdyear residents. Integrating residents into the RAFT advising and assessment process provides a context for residents to practice and exhibit activated learning behaviors.
\end{abstract}

\section{Introduction}

In the current era of rapidly advancing medical knowledge and changing clinical and administrative processes, physicians' formal education becomes obsolete in a matter of years; thus, it is important to educate physicians to develop learning practices that will sustain them throughout their professional lives. The adult learning paradigm as first articulated by Malcolm Knowles ${ }^{1,2}$ posits that adults approach their education with aptitudes and goals that differ from those of children, thus, the design of the educational experiences of adults should reflect those different needs. Ideally, adult learning environments should encourage learners' autonomy and engagement - orientations to learning that will also sustain ongoing, independent, professional practice. The paradigm of adult learning as adopted within the context of medical education empha- 
sizes that physicians learn best through problem-focused, immediately applicable, self-directed experiences. ${ }^{3-7}$ The activated (or self-activated, self-motivated, or autonomous) learner is a component of the adult learning paradigm, and has been discussed in the education field since the $1970 \mathrm{~s} .{ }^{8,9}$ Similar to autonomous learner, a term that emphasizes a (pro-)active role in the learning process ${ }^{10}$ the term activated implies that the learner is engaged in the processes and assessment of her or his education, with less emphasis on the idea of independent learning. If residency programs hope to graduate physicians who can continually learn and adapt their practices throughout their careers, supporting them to become activated learners is a significant goal for medical educators.

\section{Background: graduate medical education}

As a learning environment, medical residency uses an apprenticeship model in which physicians learn though supervised practice with relatively little time devoted to didactic teaching. When residents transition from contentoriented learning environments such as pre-medicine degrees in universities and medical schools, which traditionally involve more didactic education, they may be less prepared for the autonomous, practice-based learning environment of residency. In residency, much of the teaching and learning of medicine occurs implicitly as residents and attending physicians deliver medical care to patients. Research has described how the clinical context also includes implicit learning that is not part of the formal training but rather serves as a hidden curriculum. ${ }^{11-13}$ Particularly referring to non-scientific areas of practice such as medical ethics, the power of the hidden curriculum metaphor is that it describes how explicitly taught principles of ethics that are not reflected in actual behaviors of physicians may be soon abandoned in favor of what trainees have absorbed and internalized as a consequence of observing other physicians. A related discussion in the medical education literature pertains to physician socialization - an extensive process that underpins the development of professionalism ${ }^{14-16}$ and physician identity ${ }^{17-19}$ over time, By framing physicians' development of ethics, professionalism, and physician identity as occurring through implicit rather than explicit learning, this body of research justifies viewing the development of lifelong learning practices in a similar light. Specifically, all four constructs refer to the physician's orientation towards practice rather than knowledge of specific content, and all develop through exposure to implicit messages and activity more than delivery of didactic content. The argument of this article is that although physicians will acquire skills and strategies to support their learning over time just as they develop a sense of ethics and professionalism, their development as learners need not be left to chance. Medical educators can and should be mindful of how residents are learning to learn, and integrate experiences and practices into residency that will support activated learning.
In 2007, recognizing that residency education in family medicine was limited in terms of training physicians to meet the growing health care needs of the US population, the American Board of Family Medicine, Association of Family Medicine Residency Directors, and the American Academy of Family Practice launched a demonstration project across 14 family medicine residency programs. ${ }^{20}$ During the 5-year, active phase of the project (known as $p^{4}$ or Preparing the Personal Physician for Practice), the selected programs were challenged to implement innovative curricular changes to improve physicians' future practice. Among a constellation of other changes, the residency program that was the site of this study made adult learning principles a foundation of the redesign in order to encourage and support activated learning among the residents. Prior to the redesign, as with all other programs across the country, the family medicine curriculum was principally determined by a list of required rotations through various specialties, and a list of required hours of service or numbers of procedures performed or types of cases managed. After the redesign, the residency curriculum was supported by a set of portfolios (fields of practice with associated learning goals, objectives, and activities) and a set of family medicine competencies with articulations of standards to be met for graduation. Rather than working through checklists, residents were required to identify their personal learning needs, select or create learning activities that would help them to meet those needs, and conduct regular written assessments (both written and oral) of their progress in the family medicine competencies.

In terms of learner activation, the residency redesign represented a reversal of the customary, top-down system of education where learning activities and progress were determined by national regulations, the particular emphasis of the residency program, and faculty members' evaluations. Instead, the redesigned residency offered an environment in which residents were expected to participate in all aspects of their learning as peers and, in some ways, curators of their education. Rather than focusing on teaching residents the principles of adult learning didactically, the educational structure of the program itself was changed so as to embed expectations for residents' active learning into the activities and educational experiences of residency.

\section{Theoretical foundations}

In addition to acknowledging the relevance of the adult learning paradigm in redesigning the residency, two other constructs supported an implicit approach to encouraging learner activation-parallel process and social construction.

An influential construct known in the behavioral sciences as parallel process, ${ }^{21}$ and in education as implicit or mindful teaching, ${ }^{22,23}$ posits that a similar dynamic exists between clinician-patient communication and 
teacher-learner communication. ${ }^{24}$ Research indicates that teaching practices modeled during a resident's formal education can have lasting effects on future patient care encounters. ${ }^{25,26}$ Learners' socialization into the culture of medicine inherently shapes basic assumptions about what are acceptable and unacceptable medical practices, ${ }^{15}$ and, as already described, a growing body of literature identifies the impact of the hidden or informal curriculum in medical education. ${ }^{25-29}$ Thus, the residency redesign assumed that if residents experience supportive - activating - communication, they will replicate that communication in their care of patients. In turn, by incorporating residents' voices into educational planning, and including them as peers in that conversation, they experience participation as equal members of an interdisciplinary team, ${ }^{30}$ and are encouraged to practice ongoing self-reflection and self-assessment of their learning as graduate physicians.

With origins in sociology, the social construction paradigm focuses on language and social interaction as the principal means through which social realities (such as educational practices, institutions, organizational cultures, and belief systems) emerge and humans learn how to relate to one another. ${ }^{31-34}$ Social constructionist approaches have been adopted in a wide range of medically-related studies, including medical perception, ${ }^{35}$ emotions, ${ }^{36-37}$ disability, ${ }^{38}$ gender and illness, ${ }^{39}$ and death. ${ }^{40}$ According to the social construction paradigm, language does not merely convey neutral information, but conveys the shared assumptions of a given group. For example, medical education now uses the phrase professionalism instead of bedside manner to invoke both the breadth of impact that physicians' communication plays in clinical care, and also the centrality of competent communication to the work of being a doctor. In addition, social construction emphasizes that language exists within specific social contexts, and that social interaction within those contexts is necessary to establish meaning as individuals are habitualized in language and then internalize its implications. In this case, the family medicine residency program adopted a special language and rules of engagement related to education (such as RAFT, Educational SOAP Note, learning contracts, selectives, and so on), which constructed the residency as a collaborative and egalitarian community, and constructed the residents as activated learners. The RAFT (Resident Assessment Facilitation Team) ${ }^{41}$ represented both a structured interaction where activated learning could be encouraged, and a site where residents' activated learning might be observed.

\section{Description of the Resident assessment facilitation team}

One feature of the redesign that was intended to guide and support residents as they adopted a more central role in their education was called the RAFT - a collaborative advising and assessment process that brought faculty advisors and residents together. Medical education historically has excluded residents from participating in their own assessment, relying solely on faculty feedback to evaluate residents' educational progress. However, selfassessment is currently recognized as an important and integral part of residency education. ${ }^{42-45}$ Self-assessment processes often incorporate feedback from peers and faculty ${ }^{46}$ and, when effectively communicated, can teach residents how to view feedback as a necessary part of ongoing improvement. The resident-centered RAFT process brought together the recognized benefits of resident self-assessment with collaborative dialogue, and was designed with the following goals: i) Resist traditional hierarchical relationships among learners and faculty by enacting collaborative processes of educational planning and assessment. ${ }^{47}$ ii) Encourage resident activation and empowerment. ${ }^{20,42}$ iii) Preserve residents' sense of well-being throughout the course of the residency. ${ }^{15,41}$

Prior to the redesign, as observed by the first author and experienced by the fifth author over many years as a physician faculty member and residency director, resident assessment meetings were highly directive, critical and accomplished in the absence of the resident. Advisors subsequently summarized for the residents the outcomes of their assessment and any education plans that the faculty members and residency director had determined were necessary. In contrast, the RAFT is an interdisciplinary group that includes the resident, program director, advisor, behavioral medicine faculty member, medical educator, and residency manager. The RAFT innovation anticipated by several years the Accreditation Council for Graduate Medical Education (ACGME) requirement that all residency programs implement a Clinical Competency Committee $(\mathrm{CCC})^{48}$ for the assessment of residents. Although the RAFT addresses goals similar to the CCC by creating a team-based system for providing feedback to residents, it differs from it by deliberately including members with different disciplinary roles (rather than emphasizing physician faculty involvement) and also by including the resident as a central member of the team. The CCC is also different from RAFT because its primary responsibility is to assess resident performance. In contrast, the RAFT meeting is conducted as a group advising conversation and provides a structured review of the resident's educational activities, progress toward learning objectives and competency milestones, and reflections on learning experiences. Utilizing a set of communication principles intended to maintain safety and confidentiality, the team collaboratively addresses the resident's educational and performance concerns.

The RAFT convenes for approximately one hour per meeting: three times during internship, twice during second and third years, and with the option to call an interim RAFT if needed to adjust a resident's educational plan between scheduled RAFT meetings. Formal educational 
planning is supported with a form - an Educational SOAP Note - designed specifically for use during advising meetings between the resident and advisor, as well as for presentation during the RAFT. The form outlines individualized learning activities both completed and planned for the future, and describes progress toward competency milestones. The Educational SOAP Note provides a framework for discussion during the meeting, serving as an agenda of sorts, and, after any suggested changes have been adopted, is formally approved by everyone present as the meeting concludes.

\section{Research questions}

Preliminary investigation of the RAFT process ${ }^{21}$ indicated some success in addressing a prevailing problem of residents' loss of well-being over the course of residency. ${ }^{49,50}$ The following questions remained regarding whether and how the meetings effected a change in residents' capacities as activated learners. The theoretical assumptions of the residency redesign suggested that, by involving the residents in a dialogic process in which they played a key role in decision-making about their education, residents would both develop and demonstrate activated learning skills. Just as the hidden curriculum teaches implicitly as residents and attending physicians manage the medical care of patients, learner activation is assumed to occur as residents and the other RAFT team members attend to the business of planning educational activities and monitoring resident progress. The tenets of social construction also indicate that language and interaction constitute social realities by conveying shared assumptions and practices such as the relative power and roles of the interactants - in this case, the shared power of the RAFT members, including the resident, and the expectation that the resident plays an active role. Thus, the following questions guided the inquiry into the impact of the RAFT meeting on residents' development as activated learners:

RQ1: What are the features/functions of social interaction among RAFT team members?

RQ2: What differences (if any) can be identified in language and social interaction between first-year RAFT meetings and those that occur late in the residents' third year of training?

RQ3: What does the residents' participation in RAFT meetings imply about activated learning, particularly regarding the residents' role?

\section{Materials and Methods}

Aligned with the theoretical frameworks of parallel process and social construction that informed the development of the RAFT and other features of the residency redesign, a discursive approach was employed to examine how interaction ${ }^{51,52}$ in this context influenced the residents' development as activated learners. The term social linguis- tic analysis ${ }^{52}$ has been used to describe a focus on the discourse of a small group of people in a specific context. In this case, conversation among a group of individuals is recognized as a site of meaning and a channel through which social realities can emerge, such as the construction of the resident as an activated learner. Because the emphasis of this inquiry is on the emergence of a set of practices related to residents' behavior - activation - the social interaction of the group and what it conveys about roles and expectations for behavior is particularly salient.

\section{Sample}

The texts that were analyzed are verbatim transcripts from RAFT meetings for a single cohort of six residents from within the IRB-approved $p^{4}$ study population (enrolled residents between July 2007 and June 2012) - the only cohort for which a complete set of recorded RAFT meetings was available. To identify changes that may have occurred in residents' activation as learners through the course of the residency, two sets of meetings were selected for analysis: i) the residents' first RAFT meetings (summer of their first year) and ii) the penultimate RAFT meeting (fall of their third year). After initial review of the transcripts, it was determined that the final RAFT meeting of the residency was substantially different from all the other meetings, making it unsuitable as a point of comparison. Specifically, the final RAFT meeting typically served as an idiosyncratic conversation about each resident's entire residency experience, rather than the typical educational planning and competency assessment. Similarly, no interim RAFT sessions were included because their format varies from standard procedures related to the Educational SOAP Note. Thus, the data consisted of 12 transcripts (total $=225$ pages, mean $=18.75$ pages $)$ that were compared across the two time-points - PGY1 (post-graduate year one) and PGY3 (post-graduate year three).

\section{Data analysis}

The analysis team included two medical educators (EF - who participated in all the RAFT meetings in the sample, and ND who participates in current RAFT meetings). Because participation in the RAFT meetings might influence the analysis by imposing interpretations on the text that were not necessarily evident to others, both initial coding and member checking involved two faculty researchers ( $\mathrm{SH}, \mathrm{NB})$ who do not participate in RAFT meetings. In some cases, participation of the RAFT member who was present at the discussion helped to clarify moments of the interaction that were not easy to interpret from the transcript and recording alone. Discourse analysis is an interpretive process in which texts are examined for emergent patterns of meaning. The analysis of the RAFT transcripts followed principles of grounded theory, ${ }^{53}$ in which texts are approached inductively, and interpretations remain open until larger categories can be identified through iter- 
ative rounds of comparison to one another and across cases.

For this study, given that the topics of conversation were guided by the Educational SOAP Note (such as, updates of completed educational activities, review of competency self-assessment and discussion of formal written feedback, proposed learning activities, and so on), analysis focused not on the content or topics of conversation, but rather on what was being accomplished through the interaction among the RAFT members. In addition, the research questions centered on residents' adoption of a specific role or orientation to learning, which would be evidenced as much by what was performed through discursive interaction as by the content of what was uttered. For example, the topic of the conversation might be which clinical rotations were being proposed, but multiple social and discursive activities could be accomplished through that conversation; including, offering advice, eliciting information, offering reassurance, reflecting on past performance, and so on. Analysis occurred in five phases: i) Independent open descriptive coding: All four members of the analysis team participated in the first round with two coders per transcript including one medical educator and one researcher; coders interpreted and described in their own words what was being accomplished during each moment of the meeting. ii) Synthesis of the descriptive code sets by a third coder: Each medical educator synthesized codes on the transcripts for which they did not do initial coding, by reconciling the descriptions offered by the independent coders, and either a) offered a single descriptive code that reflected two similar interpretations, or b) retained multiple codes that interpreted the moment differently in terms of what it accomplished, and/or c) added an interpretation with an additional code. iii) Independent axial coding by both medical educators to identify common themes: Coders read through all the transcripts and associated interpretations, established consistent language that reflected themes of discursive activity identified in the initial coding, and grouped themes into categories of interaction during RAFT meetings. iv) Consensus axial coding into general categories and the development of operational definitions: The independent coders met to discuss the emergent themes and categories of interaction and to collaboratively develop the descriptive title and definition for each general category of the different activities of the RAFT meeting. Every theme was assigned to one of the general categories. Coding at this phase of the analysis was closed in that each theme was associated with only one category. v) Comparison of themes and associated categories across both sets of RAFT meetings to compare firstand third-year results: Coders compared results from each set of analyses side-by-side to identify similarities and differences of interaction between first-year RAFT meetings and third-year RAFT meetings.

As a form of member-checking to assess the plausibility of the results, the general categories and their asso- ciated themes (Table 1) were shared with the residency program director (JD, fifth author) and a faculty member who had participated in many of the RAFT meetings. The research team as a whole adjusted the wording of categories and their operational definitions until consensus was reached that the categories and themes accurately represented the transcript data.

\section{Results}

\section{RQ1: What are the features of social interaction among RAFT team members?}

Four general categories of interaction occurred during the RAFT meetings: advising, managing the process of the meeting, expressing and managing emotions, and demonstrating reflective practice and mindfulness. Operational definitions are as follows: i) Advising: interaction in which faculty members offered guidance to the resident in the form of suggestions, feedback, and information (e.g., about program procedures and regulations, options for electives, schedules, etc.). This category also included any instances in which the resident offered guidance or feedback to the residency program. ii) Managing the process of the meeting: interaction that functioned to keep the meeting on task or move the agenda forward, including clarifications of the process and metacommunication ${ }^{54}$ that ensured shared understanding among participants. iii) Expressing and managing emotions: interaction that was primarily emotional in content (expressions of feeling or eliciting conversation about emotion) or function (setting an emotional climate such as use of humor) whether expressed by faculty members or residents. iv) Demonstrating reflective practice and mindfulness: Interaction in which the resident considered past performance, identified learning needs, or offered evidence of having undertaken such reflection. This category included statements or questions from the faculty encouraging or demonstrating reflection. (Table 1)

\section{RQ2: What differences (if any) can be identified in language and social interaction between first-year RAFT meetings and those that occur late in the residents' third year of training?}

Advising. Predictably, the majority of communication in this category for both first- and third-year meetings involved discussion of feedback on resident performance and faculty advice and suggestions related to the residents' educational activities. The principal difference was that first-year meetings included more direct offers of assistance whereas in third year there were more explicit efforts by faculty to cede responsibility for educational planning to the resident. In the following PGY1 example, two faculty members offered specific advice to the resident about journaling as a self-reflective practice. Both comments are made in the same RAFT session. 
Faculty 1: There is a book that can sometimes help people get started...It's called the Cameron... The Artist's Way...she actually takes you through doing daily pages and uh just writing and reflecting. I think I've got a copy in my office if you want to borrow it.

Faculty 2: When you do that, date all of your entries, including the year. You'll be surprised... what happens is what you write leads to other things and so it's kind of a way of unpacking stuff if you just learn to let it flow, and I think the idea about "What was my day like, what was this experience like, how I've been doing, thinking, feeling, reacting?" just with the idea of getting what's inside out and making it concrete and sometimes re-reading it will be, you know, some awareness that you could've made, so your willingness... of trial and error is huge.

In both comments, the faculty members are offering spe- cific assistance to the resident who made a prior comment that $\mathrm{s}$ /he was thinking about journaling. The faculty members offer suggestions for locating books on journaling, tactics for how to journal, and provide suggestions based on their own experiences. The second faculty member is also providing a rationale for why journaling is a useful practice and how journaling can increase one's awareness.

In the following PGY3 example, the faculty member addresses the resident's concern about her/his progress on a practice improvement project by prompting reflection rather than giving advice.

Faculty: So, I mean, what do you think that would look like? If you were to feel like this whole thing was successful as a practice improvement, what... what would happen?

In this brief quotation, the faculty member poses questions directly to the resident to take ownership of her/his

Table 1. General categories and themes describing interaction during raft meetings.

\begin{tabular}{|c|c|c|}
\hline Category & PGY 1 Themes & PGY 3 Themes \\
\hline \multirow[t]{4}{*}{ Advising } & Feedback from faculty and residents & Feedback from faculty and residents \\
\hline & $\begin{array}{l}\text { Seeking and/or giving additional details by asking } \\
\text { and responding to clarifying questions }\end{array}$ & $\begin{array}{l}\text { Seeking and/or giving additional details by asking } \\
\text { and responding to clarifying questions }\end{array}$ \\
\hline & Advice-giving by faculty* & Advice-giving integrated into dialogue* \\
\hline & Offers of help and guidance from faculty** & \\
\hline \multirow[t]{7}{*}{$\begin{array}{l}\text { Expressing/ Managing } \\
\text { Emotions }\end{array}$} & $\begin{array}{l}\text { Expressions of emotion/ use of feeling words, } \\
\text { emotional disclosure, vulnerability }\end{array}$ & $\begin{array}{l}\text { Expression of emotion, use of feeling words, } \\
\text { emotional disclosure, vulnerability }\end{array}$ \\
\hline & $\begin{array}{l}\text { Supportive and affirming compliments } \\
\text { and validation statements }\end{array}$ & $\begin{array}{l}\text { Supportive and affirming compliments } \\
\text { and validation statements }\end{array}$ \\
\hline & Statements of reassurance or encouragement & Statements of reassurance or encouragement \\
\hline & Statements of gratitude and appreciation & Statements of gratitude and appreciation \\
\hline & Use of humor (e.g. self-deprecation)* & Use of humor (including in-group jokes)* \\
\hline & Personal storytelling in response to prompts* & Storytelling integrated into conversation* \\
\hline & $\begin{array}{l}\text { Discussions of self-care and wellbeing } \\
\text { in response to prompts* }\end{array}$ & $\begin{array}{l}\text { Discussions of self-care and wellbeing integrated } \\
\text { into conversation* }\end{array}$ \\
\hline \multirow[t]{6}{*}{ Managing the Meeting Process } & $\begin{array}{l}\text { Managing the flow of the session (typically initiated } \\
\text { by the Medical Educator)* }\end{array}$ & $\begin{array}{l}\text { Managing the flow of the meeting (still initiated } \\
\text { by the Medical Educator but also by the resident)* }\end{array}$ \\
\hline & Metacommunication & Metacommunication \\
\hline & $\begin{array}{l}\text { Requests for clarification or information } \\
\text { around educational process** }\end{array}$ & \\
\hline & & Comments on RAFT meeting environment as "safe"** \\
\hline & & $\begin{array}{l}\text { Group dynamic, convergence to shared process norms, } \\
\text { collaboration or cohesion** }\end{array}$ \\
\hline & & Relationship-building/side conversations** \\
\hline Demonstrating Reflective & Questions to resident encouraging self-reflection & Questions to resident encouraging self-reflection \\
\hline \multirow[t]{3}{*}{ Practice/ Mindfulness } & Self-assessment of performance* & Self-reflection integrated with self-assessment* \\
\hline & $\begin{array}{l}\text { Self-reflection on education planning } \\
\text { and personal needs* }\end{array}$ & $\begin{array}{l}\text { Reflective questions and/or statements, implicit reflection } \\
\text { on growth and development integrated into conversation* }\end{array}$ \\
\hline & & $\begin{array}{l}\text { Push-back moments where resident disagrees } \\
\text { with others' assessments** }\end{array}$ \\
\hline
\end{tabular}

RAFT, Resident Assessment Facilitation Team*Change occurring between PGY 1 and PGY 3 ,**type that appears in only one year. 
practice improvement (PI) project and instill activated learning instead of offering explicit advice for what $\mathrm{s} / \mathrm{he}$ can do to be successful. As this example demonstrates, the faculty member is encouraging the resident to figure out the necessary steps for completing the PI project.

\section{Managing the process of the meeting}

In the first-year meetings, the majority of communication related to the meeting process involved the faculty - both the medical educator whose formal role was to facilitate the meeting and other faculty members - who initiated topic changes and ensured that various RAFT functions were fulfilled. In these first-year meetings, process-related communication initiated by residents was limited to questions of clarification regarding the flow of the meeting or educational planning procedures. In the third-year meetings, residents shared responsibility for the process of the meeting and played an active role as activated learners; particularly, residents initiated topic-shifts and sometimes even the order in which parts of the RAFT conversation occurred.

As part of the PGY1 RAFT meeting, the medical educator established an opening routine by welcoming the team and outlining the RAFT agenda.

Medical Educator: So, welcome to your RAFT. Let me just review quickly what, um, what the ritual is. So, the first part is your presentation of, um, what you've been doing since you arrived, um, your self-assessment on the, the competencies that you completed, and then the plan that you have for between now and the next RAFT, and we'll have an opportunity to give you some feedback, um, ask and answer questions.

Another example of managing the meeting that frequently occurred in the PGY1 RAFT was when a faculty member would invite the resident to transition to a new topic by indicating a shift to the next topic of the meeting agenda.

Faculty 1: So, would you like to talk about sort of segueing away from this idea of where you are right now? One of the activities for this initial IEP [Individualized Education Plan] was, you know, a self-assessment of the competencies.

Resident: Okay.

Faculty 1: How did you go with that?

In this example, the faculty member not only signals a shift in topics is needed, but follows the resident's agreement with a second, more direct invitation to explain how the self-assessment went. At first, the resident does not seem to recognize that the invitation to shift topics is also an invitation to manage the discussion; and therefore, the faculty member finds a way to hand over the facilitation of the topic by asking the resident a direct question about it.

In contrast, the resident in the PGY3 RAFT initiates a shift in topic by introducing a discussion about her/his practice improvement (PI) project. Although a section of the SOAP note is labeled Plans for Upcoming RAFT, the resident is not prompted by anyone else on the team to start that part of the conversation and the resident further manages the meeting by identifying a need to receive feedback on her/his PI project.

Resident: So plans for upcoming RAFT. Um, looking at all the portfolios, um, two things that stand out that I need to do. I need to finish my research project... The other big thing that I need to work on is a performance improvement project from the Administrative and Leadership portfolio, so I was hoping to get some feedback on what I've done so far and where I could go with this...I definitely did PDSA [Plan, Do, Study, Act cycle].

Unlike the faculty members' explicit management of the agenda items in the PGY1 meetings, the third-year residents initiated topic changes (e.g., bringing the group back on track when a side conversation opened up) and introduced new topics that were relevant but not part of the RAFT agenda (e.g., how to best manage a conflict in the clinic). In this way, the residents' capacities as activated learners were evident in the sharing of meeting facilitation leadership with faculty members. A final set of themes described a different group dynamic between PGY1 and PGY3 RAFT meetings that seemed to indicate a higher degree of familiarity and comfort among the members of the team; specifically, explicit comments by residents about the safety of the interaction, a core goal in supporting an activated learner. Residents also commented on a more informal flow of conversation with cooperative overlaps and storytelling and less explicit discussion of the formal elements of the meeting (parts of the SOAP Note, for example, and forms to be completed) - themes that were not identified in the PGY1 transcript analysis.

\section{Expressing and managing emotions}

The communication in both sets of meetings included expressions of emotion (e.g., trepidation, anxiety, confidence, and pride), expressions of humor, and statements of gratitude and appreciation. The first-year meetings also included personal storytelling by the resident and discussions of self-care in response to specific prompts by RAFT members. The theme of self-care was included in this category because it was typically discussed in the context of managing stress as a lifelong learner or maintaining a sense of coping or well-being as a resident. Third-year meetings contained additional examples of humor and storytelling shared among faculty and residents, emerging as a consequence of less formal interaction. In some cases, this interaction was initially coded as side conversation, but when considered as a pattern that occurred across the PGY3 meetings, collaborative storytelling and cooperative humor seemed to indicate that residents were more confident and interacted more as peers within the team as compared with the PGY1 RAFT meetings.

In the following example of a PGY1 session, the faculty member enquires about the resident's self-care and the stress $\mathrm{s} / \mathrm{h}$ e mentioned earlier in the session. 
Faculty: So, one of the things I'm wondering about is...you also talked a little bit about how sometimes in your thinking you kind of just stress out or you think about the things that stress you out, and so I'm wondering how hard or easy it is for you to name that to ask for help to get the help you need to manage that in ways that are helpful for you?

The faculty member prompts a conversation about how the resident is managing her/his emotions based on a previous statement the resident made about things that stress her/him out. In this way, the faculty member is supporting the resident to share and encouraging her/him to reflect on the emotion and be an activated learner by expressing how easy or difficult it is to ask for help when $\mathrm{s} /$ he is stressed out. This brief example highlights how the faculty member is encouraging learner activation in the context of asking the resident to reflect on the emotion and management of it. In addition, the codes related to emotion in the PGY1 meetings include examples of RAFT faculty members expressing encouragement and support, residents expressing appreciation, and residents' occasional reference to feeling vulnerable or nervous about the residency.

In PGY3 meetings, there is a shift in who initiates the disclosure of emotion. Residents were more likely to instigate an expression of emotion as exemplified in the following quotation:

Resident: So yeah, I feel the need to take a deep breath. We had in our family a little crisis this morning, so I was up early and I'm a little high on caffeine right now. Everything's okay but we had to deal with that. ([Medical educator]: wh huh) So a little emotional from it, too, so I'm sorry about that.

In this example, the resident begins the meeting by disclosing and managing her/his emotions without being prompted. Not only does the resident name how s/he is feeling, s/he pauses to take a deep breath and disclose a family crisis that occurred earlier in the day. In naming her/his emotional state, the resident self-activates her/his involvement in the meeting and demonstrates her/his development of skills to both name and manage her/his emotional state.

One particular difference identified throughout the analysis that is worth noting was the residents' expressions of a negative emotion. In the PGY1 year, residents might briefly name a negative emotion (e.g., annoyance) but underplay its importance as in this example:

Resident: One doctor said I wouldn't do very well with, like, critical care stuff. I was kind of annoyed.

Although the resident is able to name dislike of the doctor's statement, there is no additional statement addressing how he or she will manage the negative emotion. In the PGY3 RAFT sessions, residents engaged in more extended discussion of negative emotional states as well as efforts to manage them.

Resident: I feel rested [...] I guess I've been super- stressed lately about the future, um, and finding a job and like keeping up with everything here. Um, and ignoring a lot of things about finding a job, um, and then other like personal stuff, which I've been [discussing with my advisor] a lot and, um ... all sorts of stuff that came up. Um, I started going to [community-based support group] meetings, which is pretty good.

Unlike the example in the PGY1 session, the PGY3 resident names the emotional state and mentions how $\mathrm{s} / \mathrm{he}$ is managing the stress by discussing it with her/his advisor and attending support group meetings. Interestingly, the resident also begins the example with a positive statement, I feel rested but quickly follows it with I guess I've been super-stressed...

Although the resident begins on a positive note with her/his state of wellbeing, s/he doesn't hesitate to express the stress s/he's been feeling. In this way, the resident behaves as an activated learner by demonstrating the skills $\mathrm{s} / \mathrm{he}$ has learned in managing stress and feeling safe to disclose how s/he feels to her/his fellow RAFT members.

\section{Modeling reflective practice and mindfulness}

Interaction related to reflective practice was similar in first- and third-year meetings, with residents engaging in self-reflection and self-assessment after being prompted by a faculty member. A subtle but important difference between the two sets of meetings was in the fluid, integrated quality of reflective communication in PGY3. Whereas the structure of the meeting and prepared educational SOAP note primarily dictated when and how the first-year residents would reflect on their education, third-year residents and faculty members typically engaged in reflection as part of an emergent dialogue about resident performance rather than being prompted by the structure of the meeting itself. For example, in a PGY1 session, the resident was prompted to comment on her/his video review of a patient encounter and self-identify a learning need.

Resident: I had a patient who functions well with his English but does not really comprehend and it wasn't apparent to me during the exam, but then I'm watching and like, "Wow, I'm spending a lot of time trying to understand him and he's not entirely understanding me". So that was kind of eye-opening.

In the following PGY3 meeting, the resident independently (without prompting) described a global insight into her/his own perspective on family practice.

Resident: I looked back and realized I've been doing a lot and growing a lot since April, the last time we met, um, and just thinking about where I was at that time and seeing patients and questioning my abilities and now seeing a full schedule, feeling like I can handle it, working in to handling a med student as well, and I'm really feeling a lot more confident, um, in my abilities, which is a big deal and, um, I definitely have developed a clinical style in the office which is kind of fun. It's like this is how I'm practicing medicine... realizing on a very real level 
what chronic illness means to people and hearing them talk about it, [was] really enlightening for me, and I was able to take some lessons that I learned from just those visits back to the office and remember what I was hearing from my patients, so I'm feeling that I'm moving from competent to proficient as I'm working on this.

This extended comment was given in response to the medical educator's opening prompt: We're going to begin with your narrative of what you've been doing... The resident's response - which has been significantly cut from its original 49 lines - demonstrates both the depth and breadth of her/his reflective practice as an activated learner. Many of the third-year residents illustrated similar levels of reflexivity in long monologues about their wellbeing, completion of residency activities, and perspectives about themselves as family physicians, to name a few topics. These lengthy, reflective moments by the residents were often unprompted or in response to brief, non-specific questions by the RAFT faculty members. Similar to disclosures of emotion, the resident demonstrates her/his trust in her/his fellow RAFT members to share personal insights and be actively involved in ongoing reflective practices as part of her/his education.

Finally, there were examples of reflective practice and mindfulness involving the residents' self-assessment of competence. In the following PGY1 example, the faculty member prompted the resident to reflect on her/his competency in terms of assessing readiness for more independent clinical practice.

Faculty: So one of the questions I would need to ask you is when you think about the outpatient setting and you think of we have physicals and pap tests and preventive care mixed in sometimes with all the complex behavioral stuff, um, are you at a point now where you feel really confident to jump into that vs. a, you know, few more weeks of sort of hand-holding, working in tandem with somebody while you learn the ins and outs of [the EMR system].

In this example, the faculty explicitly asks if the resident feels confident to provide care independently or if $\mathrm{s} / \mathrm{h}$ e feels the need for continued assistance. As an intern, the resident does not behave as an activated learner by initiating a self-assessment. In the PGY3 year, there is less prompting by the faculty and more instigation by the residents to reflect on internal processes to determine their own competence. In the following example, the faculty members ask for clarification when the resident indicates discomfort with the idea of claiming to be competent; the resident, however, is the one who names his/her sense of competence.

Faculty 1: Because if you were to actually name, use a reference of competence, what would you have to accept... about yourself?

Resident: Like if...that I'm getting more competent, becoming more competent...

Faculty 2:...do you feel there is barrier inside of you or outside that's causing you to not advance?
Resident: I don't think that I'm not advanced. I feel comfortable. I think that, you know, before I used to look at my schedule and have a headache and have palpitations and be nervous and like...but now I feel like, whatever. It's all right, I can manage, whatever it is.

In this exchange, the faculty members attempt to understand the resident's level of readiness for independent practice and her/his associated feelings. By asking a few questions, the resident names her/his growth in competence and confidence in managing patient care as a result of both prior self-reflective practice and the RAFT group interaction. The example also highlights the resident's disagreement with the faculty's suggestion that $\mathrm{s} / \mathrm{he}$ is not advancing and plays an active role in assessing her/his own competence.

RQ3: What does the residents' participation in RAFT meetings imply about activated learning, particularly regarding the residents' role?

In the category of advising, RAFT interaction indicated a shared practice of integrating feedback, assessment, reflection, and advice-giving into educational decision-making that included the resident as a key player on the team. By the third-year RAFT meetings, examples of "advice-giving" by faculty members were less frequent, and advice was typically integrated into dialogue and negotiated between resident and faculty members. The theme of offers of help and guidance was not noted in the PGY3 meeting transcripts, but there were numerous examples of efforts to hand decision-making back to the resident, which implicitly communicated both confidence in the residents' ability to problem-solve independently, and an expectation that they should do so in the context of the RAFT conversation.

The category of expressing and managing emotion produced the widest range of themes describing interaction, and the most consistency between first- and thirdyear meetings in terms of shared themes. Both sets of meetings integrated expressions of emotion, statements of encouragement and gratitude, and humor, and descriptions of self-care; although the later meetings were characterized by more fluid and integrated references to emotions and self-care as residents told and reflected on their own stories of residency. The RAFT interaction established a practice of expressing and discussing emotions as part of the residents' education, rather than treating the discussion of emotions as belonging only to a discursive context such as psychological counseling or professional support group. By encouraging disclosure of and reflection on the emotions that residents experienced during their education - including those experienced in response to patient care - the RAFT interaction signaled that reflecting on one's emotions serves an important purpose in activated learning. In some cases, emotional disclosures resulted in expressions of empathy and support, and in other cases residents were prompted to reflect on emo- 
tions (such as reluctance to claim competence) in order to facilitate their learning.

Activities related to managing the process of the meeting were at first the purview of faculty members and later became the responsibility of residents. In many cases, residents simply adopted more of a leadership role by the PGY3 meeting and took responsibility for identifying what topics they wanted to address at what time during the meeting. RAFT faculty members continued to influence the flow of conversation by asking questions or (in the case of the medical educator) reminding the group about the RAFT agenda, but the general movement of the responsibility for the content of the meeting from faculty to resident implied that educational planning and determining competence were the purview of the residents as activated learners.

Also by the end of residency, communication that indicated self-reflection and mindfulness was seamlessly integrated into conversations of educational progress rather than needing explicit prompting from the faculty members. Thus, the RAFT interaction demonstrated that selfreflection, particularly in the context of conversations with others, is an expected and worthwhile feature of activated learning. Residents became comfortable telling stories of their educational experiences and reflecting on what those experiences meant for them as learners and as physicians anticipating independent future practice.

\section{Discussion}

Analysis indicated that interaction during the RAFT meetings addressed practical exigencies of learning such as setting goals and establishing educational activities ( $\mathrm{ad}$ vising), as well as the facilitation of the meeting itself (managing the process of the meeting). However, even in communication that served administrative functions, residents' engagement in these functions by their third year indicated increasing activation of their learning. Familiarity with the process and comfort with the faculty members may account for some of the changes in interaction observed during third-year meetings. However, the more fluid integration of topics such as self-care and emotional responses to learning, as well as the occasional push back from thirdyear residents when they disagreed with faculty members' ideas suggest that residents also had become comfortable with a more active and authoritative role in their learning.

A number of implications may be offered. i) The RAFT provides a planned context in which skills of activated learning - including self-reflection and self-assessment, mindfulness, emotional disclosure and reflection can be encouraged and practiced. ii) By recasting learners and teachers as collaborators in educational processes, the RAFT offers an alternative to traditional models where assessment and educational planning are separate activities and evaluation of learners is accomplished by faculty members independent of dialogue with residents. In this model, the residents take on more responsibility for triangulating others' feedback with their self-assessment to inform educational problem-solving which, ideally, will continue as part of their professional, lifelong learning. iii) The process of encouraging activated learning is developmental in that advising by RAFT faculty members evolves with the resident. First-year residents can receive more direct advice-giving and problem-solving and, by third year, residents can be encouraged to assume responsibility for identifying and meeting their educational needs. iv) The four major categories of interaction during the RAFT, supported by its formal structure, are complementary in function (e.g., advising is accomplished with emotional awareness and sensitivity; reflecting on performance is a key aspect of advising; all play a role in supporting residents' activated learning).

It should also be noted that in order to provide resident assessment and advising meetings that encouraged the residents to adopt activated learning behaviors, substantial discussion occurred among the faculty, not only about the structure that would be required but also about the communicative processes and the values that should underlie the approach, with trust and safety as core goals. Furthermore, the RAFT (or any similar process) depends upon the culture of the residency, including complementary educational innovations and the members' investment in being self-reflective and mindful, and applying emotional sensitivity while interacting with one another, both within and outside the assessment process.

The data set was robust for identifying the characteristics of this group's interaction as it differed across two time points. However, it represented only one cohort of residents and so it cannot be claimed that the sub-themes would replicate exactly with another cohort. Future research might expand the sample and repeat the analysis with examples of interim (special purpose) RAFT meetings. Also, reflecting on the RAFT as an educational intervention beyond activated learning, a number of questions remain, particularly regarding its impact on residents' development of communication skills and professionalism, team-based practice, and relationship-centered care of patients. As it stands, however, the categories and descriptions of interaction from this analysis allow other medical education programs to consider the influence of discourse and how discursive contexts (such as assessment and advising meetings) can serve as opportunities to encourage, guide, and observe residents' adoption of activated learning practices.

Like any other educational experience, the RAFT is deemed successful when residents and faculty alike are able to transfer skills of activated learning from the RAFT into other educational or clinical contexts. One third-year resident expressed the value of the RAFT meetings as a time for reflection and self-assessment:

I appreciate having to go through this process because...it's an eye-opener... as to [how] far you've gone or what you've not done that you should have 
done and also what you plan on doing in the future so, it's actually... a good thing for me to be able to...sit down and have it on paper and be able look it from my previous RAFT and compare it.

The hope and expectation is that, having practiced these skills of active learning in residency, the residents will retain an active orientation towards their learning, and these skills will sustain them throughout their professional lives.

\section{References}

1. Knowles MS. The modern practice of adult education: from pedagogy to andragogy. Englewood Cliffs, NJ: Cambridge Book Company; 1988.

2. Knowles MS, Holton III EF, Swanson RD. The adult learner: the definitive classic in adult education and human resource development. 6th ed. Amsterdam: Elsevier; 2005.

3. Shin JH, Haynes RB, Johnston ME. Effect of problembased, self-directed undergraduate education on life-long learning. CMAJ 1993;148:969-76.

4. Loyens SM, Magda J, Rikers RM. Self-directed learning in problem-based learning and its relationships with self-regulated learning. Educ Psychol Rev 2008;20:411-27.

5. Miflin BM, Campbell CB, Price DA. A conceptual framework to guide the development of self-directed, lifelong learning in problem-based medical curricula. Med Educ 2000;34:299-306.

6. Mamary E, Charles P. Promoting self-directed learning for continuing medical education. Med Teach 2003;25:188-90.

7. Murad MH, Coto-Yglesias F, Varkey P, et al. The effectiveness of self-directed learning in health professions education: a systematic review. Med Educ 2010;44:1057-68.

8. Lindvall CM, Bolvin JO. The role of the teacher in individually prescribed instruction. Educ Technol 1970;10:37-41.

9. Rohwer Jr. WD, Levin JR. Elaboration preferences and differences in learning proficiency. Paper presented at the Annual Meeting of the American Educational Research Association. 1970 March, Minneapolis, MN.

10. Thanasoulas D. What is learner autonomy and how can it be fostered. Internet TESL J 2000;6:37-48.

11. Hafferty FW. Beyond curriculum reform: confronting medicine's hidden curriculum. Acad Med 1998;73:403-7.

12. Hafferty FW, Franks R. The hidden curriculum, ethics teaching, and the structure of medical education. Acad Med 1994;69:861-71.

13. Haidet P, Stein HF. The role of the student-teacher relationship in the formation of physicians. The hidden curriculum as process. J Gen Intern Med 2006;21;S16-20.

14. Al-Eraky MM, Marei HF. Professionalism in medical education. Adv Health Sci Educ Theory Pract 2015;1:37-40.

15. Hilton S, Southgate L. Professionalism in medical education. Teach Teach Educ 2007;23:265-79.

16. Rhodes R, Cohen D, Friedman E, Muller D. Professionalism in medical education. Am J Bioeth 2004;4:20-2.

17. Apker J, Eggly S. Communicating professional identity in medical socialization: considering the ideological discourse of morning report. Qual Health Res 2004;14:411-29.

18. Jarvis-Selinger S, Pratt DD, Regehr G. Competency is not enough: integrating identity formation into the medical education discourse. Acad Med 2012;87:1185-90.

19. Pratt MG, Rockmann KW, Kaufmann JB. Constructing pro- fessional identity: the role of work and identity learning cycles in the customization of identity among medical residents. Acad Manage J 2006;49:235-62.

20. Green LA, Jones SM, Fetter G Jr, Pugno PA. Preparing the personal physician for practice: changing family medicine residency practice to enable new model practice. Acad Med 2007;82:1220-7.

21. Shapiro J. Parallel process in the family medicine system: issues and challenges for resident training. Fam Med 1990;22:312-9.

22. Kernochan RA, Mccormick DW, White JA. Spirituality and the management teacher reflections of three Buddhists on compassion, mindfulness, and selflessness in the classroom. J Manag Inq 2007;16:61-75.

23. Wolff-Burke M, Ingram D, Lewis K, et al. Generic inabilities and the use of a decision-making rubric for addressing deficits in professional behavior. J Phys Ther Educ 2007;21:13-22.

24. Kern DE, Branch WT Jr., Jackson JL, et al. Teaching the psychosocial aspects of care in the clinical setting: practical recommendations. Acad Med 2005;80:8-20.

25. Haidet P, Kelly PA, Chou C. Characterizing the patient-centeredness of hidden curricula in medical schools: development and validation of a new measure. Acad Med 2005;80:44-50.

26. Haidet P, Dains JE, Paterniti DA, et al. Medical student attitudes toward the doctor-patient relationship. Med Educ 2002;36:568-74.

27. Hafler JP, Ownby AR, Thompson BM, et al. Decoding the learning environment of medical education: a hidden curriculum perspective for faculty development. Acad Med 2011;86:440-4.

28. Stein HF. American medicine as culture. Boulder, CO: Westview Press; 1990.

29. Stern DT. In search of the informal curriculum: when and where professional values are taught. Acad Med 1998;73:S28-30.

30. Orchard CA, Curran V, Kabene S. Creating a culture for interdisciplinary collaborative professional practice. Med Educ Online 2005;10:1-13.

31. Atkinson P, Gregory M. Constructions of medical knowledge. In: Holstein JA, Gubrium JF, eds. Handbook of constructionist research. New York: Guilford; 2008, pp 593-608.

32. Berger PO, Luckmann T. The social construction of reality: a treatise in the sociology of knowledge. New York: Anchor Books; 1967.

33. Foster E, Bochner AP. Social constructionist perspectives in communication research. In: Holstein JA, Gubrium JF, eds. Handbook of constructionist research. New York: Guilford; 2008. pp 85-106.

34. Gergen KJ. Realities and relationships: soundings in social construction. Cambridge, MA: Harvard University Press; 1994.

35. Foucault M. The birth of the clinic: an archaeology of medical perception. New York, NY: Vintage Books; 1994.

36. Loseke DR, Kusenbach M. The social construction of emotion. In: Holstein JA, Gubrium JF, eds. Handbook of constructionist research. New York: Guilford; 2008. pp 511-30.

37. McNaughton N. Discourse(s) of emotion within medical education: the ever-present absence. Med Educ 2013;47:71-9.

38. Rice S. The social construction of "disabilites": the role of law. Educ Stud 2003:169-80. 
39. Lorber J, Moore LJ. Gender and the social construction of illness. 2nd ed. Lanham, MD: Altamira Press; 2002.

40. Seale C. Constructing death: the sociology of dying and bereavement. Cambridge, UK: Cambridge University Press; 1998.

41. Foster E, Biery N, Dostal J, Larson D. RAFT (Resident Assessment Facilitation Team): supporting resident well-being through an integrated advising and assessment process. Fam Med 2012;44:731-4.

42. Acreditation council for graduate medical education. Common program requirements. Chicago, IL: ACGME; $2016 \mathrm{Jul}$ 1. Available from: http://www.acgme.org/Portals/0/PFAssets/ProgramRequirements/CPRs_07012016.pdf

43. Sargeant J. Toward a common understanding of self-assessment. J Contin Educ Health Prof 2008;28:1-4.

44. Sargeant J, Mann K, van der Vleuten C, Metsemakers J. "Directed" self-assessment: practice and feedback within a social context. J Contin Educ Health Prof 2008;28:47-54.

45. Sargeant JM, Mann KV, van der Vleuten CP, Metsemakers JF. Reflection: a link between receiving and using assessment feedback. Adv Health Sci Educ Theory Pract 2009; 14:399-410.

46. Plant JL, Corden M, Mourad M, et al. Understanding selfassessment as an informed process: residents' use of external information for self-assessment of performance in simulated resuscitations. Adv Health Sci Educ Theory Pract 2013;18: 181-92.

47. Hirschmann K. Blood, vomit, and communication: the days and nights of an intern on call. Health Commun 1999; 11:35-57.

48. Colbert CY, Dannefer EF, French JC. Clinical competency committees and assessment: Changing the conversation in graduate medical education. J Grad Med Educ 2015;7:162-5.

49. Bellini LM, Shea JA. Mood change and empathy decline persist during three years of internal medicine training. Acad Med 2005;80:164-7.

50. Martin AR. Stress in residency: a challenge to personal growth. J Gen Intern Med 1986;1:252-7.

51. Hodges BD, Martimianakis MA, McNaughton N, Whitehead C. Medical education...meet Michel Foucault. Med Educ 2014;48:563-71.

52. Phillips N, Hardy C. Discourse analysis: investigating processes of social construction. Thousand Oaks, CA: Sage; 2002.

53. Corbin J, Strauss A. Basics of qualitative research: technologies and procedures for developing grounded theory. 4th ed. Thousand Oaks, CA: Sage; 2015.

54. Watzlawick P, Beavin JH, Jackson DD. Pragmatics of human communication. New York, NY: Norton; 1967. 